\title{
Publisher Correction: Engineering crystal structures with light
}

Ankit S. Disa (D), Tobia F. Nova (iD) and Andrea Cavalleri (D)

Correction to: Nature Physics https://doi.org/10.1038/s41567-021-01366-1, published online 4 October 2021.

In the version of this Perspective originally published, there were errors in the reference numbering and in the format of Table 1 . In the original version, ref. 34 (Stupakiewicz, A. et al. Ultrafast phononic switching of magnetization. Nat. Phys. 17, 489-492 (2021)) should have been ref. 35, and ref. 74 (Khalsa, G. \& Benedek, N. A. Ultrafast optically induced ferromagnetic/anti-ferromagnetic phase transition in $\mathrm{GdTiO}_{3}$ from first principles. npj Quant. Mater. 3, 15 (2018)) should have been ref. 34. The original refs. 34-73 have now become 35-74, and Khasla \& Benedek are now ref 34. In Table 1, first "Nonlinearity" column, there were errors in the format of the second term of the first row, where " $Q_{\text {driven }}^{1}$ " and " $Q_{\text {driven }}^{2}$ " now appear as " $Q_{\text {driven,1 }}$ " and " $Q_{\text {driven,2 }}$ ".

These errors have been corrected in the online version of this Perspective.

Published online: 6 January 2022

https://doi.org/10.1038/s41567-021-01447-1

๑) Springer Nature Limited 2022

\section{Author Correction: Characterization of the shape-staggering effect in mercury nuclei}

B. A. Marsh, T. Day Goodacre, S. Sels, Y. Tsunoda, B. Andel, A. N. Andreyev, N. A. Althubiti, D. Atanasov, A. E. Barzakh, J. Billowes, K. Blaum, T. E. Cocolios, J. G. Cubiss, J. Dobaczewski, G. J. Farooq-Smith, D. V. Fedorov, V. N. Fedosseev, K. T. Flanagan, L. P. Gaffney, L. Ghys, M. Huyse, S. Kreim, D. Lunney, K. M. Lynch, V. Manea, Y. Martinez Palenzuela, P. L. Molkanov, T. Otsuka, A. Pastore, M. Rosenbusch, R. E. Rossel, S. Rothe, L. Schweikhard, M. D. Seliverstov, P. Spagnoletti, C. Van Beveren, P. Van Duppen, M. Veinhard, E. Verstraelen, A. Welker, K. Wendt, F. Wienholtz, R. N. Wolf, A. Zadvornaya and K. Zuber

Correction to: Nature Physics https://doi.org/10.1038/s41567-018-0292-8, published online 1 October 2018.

In the version of the article originally published, an affiliation was missing for N. A. Althubiti. The Physics Department, Faculty of Science, Jouf University, Aljouf, Saudi Arabia should have been included.

Published online: 24 January 2022

https://doi.org/10.1038/s41567-022-01503-4

(c) The Author(s), under exclusive licence to Springer Nature Limited 2022 